\title{
CONDITIONS OF INVESTMENT DECISION-MAKING IN AREA OF RFID TECHNOLOGY
}

\author{
Marzena Jankowska-Mihułowicz ${ }^{1}$, Piotr Jankowski-Mihułowicz ${ }^{2}$
}

\begin{abstract}
The application of the electronic product code (EPC) in an enterprise may turn out to be one of the choices in the future. The subject of this article is an analysis preceding decisive conditions in an investment process of its implementation. These reflections are preceded by the research in Polish enterprises, aiming at an estimation of the possibility of the RFID (Radio Frequency IDentification) transponder commercialisation (market potential) being consistent with the EPC requirements. Conducting such research in the future will lead to a decrease in the decision gap among managers within the scope of the possibility of implementing the innovative solution described, as well as the anticipated business results. Methods of analysis and synthesis have been applied, within the theory of decision-making and telecommunications. An interdisciplinary approach to the issue in question constitutes the added value of this article.

The conclusion comprises a synthesis of the article contents - crucial decisive areas that require monitoring and simultaneous estimation (now and in the future) regarding implementation of the electronic product code in an organization. In general, these areas are macro environment, competitive environment, strategic potential of an organization, and managers' decisiveness.
\end{abstract}

JEL Classification Number: D81, DOI: http://dx.doi.org/10.12955/cbup.v2.446

UDC Classification: 005.33

Keywords: decision-making, decisiveness, EPC, risk management, RFID, semi-passive transponder

\section{Introduction}

Contemporary enterprises function under conditions of globalization and turbulent environment, in which certain processes occur and result in new numerous and complex decisive problems. The changes described take place in all areas of an environment, including both technical and technological, as well as lead to disproportion between competitors in the market. Managers' decisions, considering the application of the latest technical solutions in an enterprise, may lead to progress and achieving leadership. Nonetheless, they are associated at the same time with high uncertainty. Implementing the standard of the electronic product code (EPC) in an enterprise constitutes a strategic decision of this type. Decisions, if poorly judged and hastily made, may lead an organization into crisis.

In the years 2012 through 2015, research is being conducted with the aim of developing a laboratory model of the autonomous semi-passive transponder, which does not require classic battery power, and is designed for the RFID (Radio Frequency IDentification) systems application. Subsequently, on the basis of the laboratory model, there is a plan to create the device prototypes and to estimate both the market potential of the RFID transponder, consistent with EPC requirements, and possibilities of its commercialization.

The subject matter of this paper concerns the characteristics of decisive conditions that are essential in the process of implementing the autonomous semi-passive transponder in Polish enterprises, which does not require classic battery power and is consistent with the EPC standard - determined later on as a result of this article.

The main objective of this article is to specify crucial decisive areas, which are essential in order to successfully implement the product in a organization. The product, being the subject of consideration, is not present in the market yet; and investment decisions regarding its application in an organization will be made in the future under conditions of high risk and uncertainty. The hypothesis has been

\footnotetext{
${ }^{1}$ Marzena Jankowska-Mihułowicz, Rzeszow University of Technology, Rzeszow, Poland, mjanko@prz.edu.pl

${ }^{2}$ Piotr Jankowski-Mihułowicz, Rzeszow University of Technology, Rzeszow, Poland, pjanko@prz.edu.pl
} 
acknowledged that making investments decisions associated with implementing a new technical solution in an organization requires conducting a multiple-criteria, simultaneous decision analysis of conditions in the areas of organization environment, its strategic potential, as well as cognitive processes of a subject of decision.

Methods of analysis and synthesis have been applied, within the theory of decision-making and telecommunications. An interdisciplinary approach to the issue in question constitutes the added value of this article.

\section{Literature Review}

As the most common reasons for investment decision-making, regarding the implementation and maintenance in the organizations, new solutions in the field of RFID indicated: competitive pressure and operational efficiency (process innovation, improved information visibility, greater data accuracy, service quality, and track-and-trace capabilities) (Keating, Coltman, Fosso-Wamba, \& Baker, 2010); expansion of the application area from inventory management to location tracking and also supply chain management in a wide range of industries; the beneficial potential impacts on cost, customer satisfaction, and operational efficiency (Lee \& Lee, 2012); complementation of Lean Manufacturing by addition of RFID technologies to the manufacturing process (Chongwatpol \& Sharda, 2013); reduction in handling and checking, increase of information visibility, and speed of process, when it is integrated with an appropriate decision management system; potentially large savings through traceability and control of products quality and safety (Butcher \& Grant, 2012).

Results of researches indicated that the implementation effects of RFID into supply chain management showed multidirectional and complicated influencial relationship; RFID plays an important role in the procurement of resources, production process, transport, loading, unloading, warehouse, etc. (Ha, Park, Lee, \& Park, 2013). Moreover, in literature on the subject, attention is paid toward ethical problems of RFID system-related vulnerabilities in existing supply chain applications (Zhou \& Piramuthu, 2013).

\section{Macro environment conditions}

Applying radio identification devices in commercial applications is more common and possible thanks to contemporary achievements in science and technology. The progress within this field of study allows the finding of new solutions, characterized by better functionality and autonomy. A frequent lack of specification (by manufacturers) of crucial parameters of available devices, occurring at the current stage of knowledge, is the main reason for hampering the practical implementation of multiple object identification (communication process is conducted alongside with many transponders), and for implementation of automated processes under dynamic conditions (alternating organization and/or object orientation in space). Ineffective and time-consuming method of trial and error, being commonly used in configuration of the system in question, does not provide reliable information on functioning of the automated system with satisfactory identification efficiency. The ability to assess a basic parameter (an area of proper work of the RFID system for the required application) assists in obtaining a complete information set, which is imperative to overcome the development barrier of many branches within the framework of a socioeconomic activity.

There is a belief, held in the awareness of distributors of currently available RFID devices, that their products meet all the needs of the market. Practice indicates that a problem appears right after the realization of a investment, while implementing the RFID systems. Achieving low efficiency of the marked objects identification frequently leads to decreasing the forecast, due to its effect on the 
business plan, and in some extreme cases results in a necessity to withdraw from the implementation during its realization, along with the acceptable losses.

To sum up, first of all, there is no electronic transponder that is applicable in every RFID application. Secondly, no parameters of the devices available are specified, which does not enable a rational approach to implement the radio frequency identification identification systems. Thirdly, despite the declared demand there are not enough transponders on the market that provide the implementation of additional autonomous functions (independent from additional devices).

In many research centers throughout the world, comprehensive studies on the synthesis of an unified system are conducted. In the foreseeable future, the system will allow a broad replacement of currently used barcodes, with radio transponders, consistent with the EPC. Those activities are to provide an efficient realization of automatic process identification with regard to fast moving consumer goods (FMCG) in global supply chains (Brown, 2007). Similar activities concern the systems development and implementation, which will provide a reliable and safe identification in the future as far as objects in the area of rail and road transport are concerned (realization of Automatic Vehicle Identification processes-AVI) (Bartneck, 2009). The subject of the rest of currently used and developed RFID applications consists of widely understood automatic identification processes in security and access controlling systems in industrial logistics, during the identification of measuring samples or materials in research processes, as well as in other fields of social and economic activity (Hitzer, 2010; De la Giroday, 2010; Parks, 2009; Harrison, 2009).

Firstly, an idea of the product commercialization is conditioned by main faults present in the construction of the semi-passive RFID transponders that considerably limit the possibilities of their broad application in automated processes. Secondly, the idea results from the trend of seeking alternative solutions or the use of already existing energy sources, which are present in the RFID working environment.

The considerable part of the application potential of the product is located in the area of the Internet of things, which is based on the RFID devices, consistent with the electronic product code. Taking into account activities undertaken by the European Commission (EC) in this field, it follows that intensive application research envisaged in the years 2010 through 2015. The research will be conducted within the scope of obtaining renewable energy from different sources and gathering it effectively in the structure of semi-passive transponders (Working Group RFID, 2008). It is assumed that the development of electronic systems and permanent reduction of energy demand of transponders chips and their supplementary systems will occur at the same time, by means of which the autonomous functions in the semi-passive systems will be realized. As anticipated by the EC and confronted with assumptions of world economic development, the years 2015 through 2020 should be committed for an integration of semi-passive autonomous transponders with marked objects, as well as for their intensive commercialization in the area of many fields of socioeconomic activity. As far as intensive development of nanotechnology materials is concerned, in the years following 2020, the utter dissemination of the semi-passive autonomous solutions (intelligent objects) is anticipated. They will include a biodegradation function - a self-destruction in the work environment, a possibility for the semi-passive transponders to be integrated with living organisms.

An important objective regarding the dissemination of standardized solution of the semi-passive transponders, consistent with the EPC, is to gain predictability of their parameters. The application usefulness of a laboratory model, which is the basis for the development of prototypes intended for commercialization, is conditioned by a realistic estimation of a device performance under actual conditions. Moreover, it is necessary, in predicting quantitatively, to increase the geometric size of the interrogation zone towards popular, passive RFID systems as well as dynamics of objects liable to 
recognition. In addition, providing a perspective of integration within a transponder structure with regard to devices of low energy consumption, which allows autonomous realization of additional functions in the system with no use of a read/write device (RWD) and its antenna, will make it possible to control the storage and usage of marked objects (e.g. fast moving consumer goods, which need to be preserved in certain environmental conditions). In this context, the assumed product functions are converging with development plans as far as the area of the RFID semi-passive application systems is concerned.

The planned activities are mirrored in international assumptions with regard to standardization activities within the framework of the RFID technique, supported by the EC under the GRIFS program (Global RFID Interoperability Forum for Standards, 2014), especially referring to the thematic area of "Conformance \& Performance." The innovative character of such research in the application area of the FMCG branch has been highlighted in the assumptions of the international BRIDGE project (Building RFID for the Global Environment, 2014), in which the resolution of barriers to the implementation of the RFID technique based on the electronic product code solutions was anticipated. The same premises serve as a basis for activity of the European CE RFID platform (Coordinating European Efforts for Promoting the European RFID Value Chain, 2014), whose subject matter constitutes supporting the RFID technique development as well as increasing the European market competitiveness through the political environment consolidation.

In times of intensive development of the network of roads and highways, together with permanently increasing intensity of transport and road and rail traffic, there is a justified necessity to control and manage this traffic. One of the examples of application is "viaTOLL" (General Director for National Roads and Motorways, 2014), an electronic toll charging system in which the "viaBOX" is an active electronic board device installed with permanent control and operating activities. It has been functional in Poland since July 2011 on payable sections of highways, expressways, and national roadways. In further perspective, there is a necessity to identify vehicles with an access to restricted areas. Those needs stem from an intensive establishment of separated areas of controlled access namely, parts of a city accessible only by a particular group of vehicles (e.g. emergency or technical response units). The objective of every effort, aiming at the AVI processes realization, is, therefore, a choice for implementating a system that will provide robust, reliable, stable and, above all, dynamic vehicles identification, which allows simultaneous tracking in real time. The assumptions formulated indicate the usage of potentially inexpensive and maintenance-free RFID semi-passive devices, which may be applied in a vehicle marking area or in a place where the process of their automatic identification is conducted - both by the means of mobile and fixed RWD.

The product may also support an organizational development within the scope of the "Internet of things" information society. Under the Foresight Program for the Subcarpathia region (Woźniak, 2008), the RFID technique issues were ranked at the top of the list with utmost significance for development.

\section{Competitive environment conditions}

Unique product features will make it possible to improve many business processes in potential receivers. As distinct from a barcode, the semi-passive transponder consistent with the EPC will be a carrier of numerous specific information regarding an item, e.g. country of origin, manufacturer, price, value, number of pieces in a container, expiration date, storage conditions (temperature and humidity for transport), and much more. Mass application of the transponders in question, with relatively low costs, will make it possible to meet even the most sophisticated customers' needs. Adjusting the variants of the product to the customers' needs and expectations (especially strategic ones) will enhance relations with them. Decisive criteria should be determined within this scope in the following 
matter: type, urgency, frequency, and operating cost. Organizations that will implement the new unique product have a chance to win over more customers from their competitors and, as a result, enhance their own competitive edge against their rival companies in the market.

Financial profitability of the production by the semi-passive transponders providers may be considered on the basis of analogy to the currently produced passive transponders.

In the last decade of the $20^{\text {th }}$ century, the idea of production expense limit with regard to a single RFID transponder was developed in research and business circles (e.g. inter alia Auto ID Labs, WalMart, etc.). The idea is expected to enable an intense increase in dissemination of the RFID technique in a branch of FMCG industry (Giusto, Iera, Morabito, \& Atzori, 2010; Manish \& Shahram, 2005). The expense was determined at $5 \varnothing$ for a single classic passive RFID transponder, appearing in the form of a label (Sarma, 2001). Apart from developing effective technological processes that enable cheap and massive production of these devices, it was also necessary to determine the conditions and regulations with respect to the proper work of RFID devices in the area of FMCG.

At the current stage of knowledge and development of the RFID technique, the standardization (EPC, ISO/IEC, EN/ETSI) and production (inkjet printing, inlays assembly) processes may be considered so developed. It is possible to launch mass production, with the development of new materials and printed electronics technology, which will reduce in cost, while accommodating an increasing need for RFID electronic transponders in the form of labels (Giusto, Iera, Morabito, \& Atzori, 2010; Yan, Zhang, Yang, \& Ning, 2007; Turcu, 2010). The need is already substantial, but there are many a time the realization in leading providers, encompassing hundreds and even millions of pieces, is elongating. In this context, as far as economics is concerned, one may notice favorable conditions to make decisions favoring the development of semi-passive systems over the passive ones. The estimation (for potentially undertaken development and implementation works in the future) of realistic expense in the mass production of the proposed semi-passive transponders, with an alternative power supply source, is still a great problem in this aspect. It should be understood, nonetheless, that in recent years the production expense of the passive transponders has been reduced several times and a further dip is anticipated (Schuster, Allen, \& Brock, 2007; Turcu, 2010). Despite the apparent offers (e.g. in the Chinese market) of passive inlays at the expense of $5.8 \varnothing$ with the minimum order of five million pieces (RFID News, 2009), the process of reaching the established limit of $5 \phi$ per passive RFID transponder in the form of a label may require a few more years. In fact, it will be dependent on technological opportunities, proficiency, as well as assembly lines availability of the providers. Achieving an analogical economic effect for the product in question should be possible in further perspective, which is confirmed by the EC report.

In compliance with the operating pattern of producing the passive RFID transponders (in the form of labels) in their costs of mass production, one may distinguish three general elements: purchase of chips, the cost of transponders (inlays) production, and the cost of turning transponders into labels. Mass production cost, over 1 million copies, of the passive transponders is estimated to be around 9.25 to $18.75 \notin$ per piece. Turning the transponders into labels is also a part of the production, whose expense is dependent inter alia on the kind and number of layers protecting the inlay inside the label, as well as on the graphic design, which is printed on the outside (thermal transfer and offset printing). This part of the mass production may cost about 3 to $9.25 \phi$ for turning one single inlay into a transponder-a label.

The foreseen complexity of the semi-passive transponder structure, with the current estimate of production cost, may result in their unit price being several percent higher than that of the passive transponders. Manufacturers' application of the market development strategy concerning the product will allow territorial expansion and achieving the scale effects. Thus, there is a justified probability 
that production will quickly become profitable and prices of the semi-passive transponders will be reduced within a few years.

\section{Internal organizational conditions}

Project management is considered crucial in order to determine the organizational conditions for making investment decision on new product implementation within an organization (the autonomous semi-passive transponder, which does not require classic battery power, consistent with the EPC),. Nowadays, there are nine areas in project management knowledge, including integration, scope, time, cost, quality, human resource, communications, risk, and procurement. All of these areas of knowledge are important in the investment decision-making; however, the project manager can determine the most important ones, which have the greatest impact on the outcome of the project (Banaitiene \& Banaitis, 2012). Baysan \& Ustundag (2013), Cevikcan \& Ustundag (2013a), and Cevikcan \& Ustundag (2013b) referred to three important areas of investment decisions regarding RFID, which are:

1. Project cost management: hardware cost (transponders, read/write devices, antennas etc.), middleware cost (middleware, other softwares), service cost (implementation, test, training, and business process reengineering), and maintenance cost (periodic maintenance and technical support operations).

2. Project integration management-it is necessary to pay close attention to the needs of participants within the supply chain in folowing implementation aspects: implementation time, oganizational learning, process re-engineering, upgrade ability, compatibility with existing information technology (IT) and information system (IS), and also experience about technology (depending upon the the level of advancement of technology).

3. Project risk management: private risks (complexity risk, user risk, structural risk, organizational risk, and team risk) and public risks (competition risk and market risk).

In managing project cost, the decision-making process manager should take into account the benefits of the investments in the following cost reduction areas of RFID (Cevikcan \& Ustundag, 2013a):

1. Cost reduction in labor - increasing automation and acceleration of processes, reducing working costs, increasing accuracy and work efficacy, strategically reallocating resources, and broadening the working scale.

2. Cost reduction in inventory - realization of Just In Time (JIT) assumptions: registering processes in real time, increasing the accuracy of anticipating the demand, improving storage economy, reducing supplies, accelerating the orders cycles, and reducing the storage costs.

3. Cost reduction in shrinkage - an increase in supplies control (decreasing the theft and expired products), an increase in safety (tracking the product in storage and distribution processes), and the tracking of product life time.

4. Cost reduction in lost sales - identifying products and assortment availability, improving sale conditions, stocktaking and customer satisfaction

Proper strategic adjustment of the new product to an organization makes it possible to achieve an increase in the marketshare and in potential income, hence, profitability of a financial investment in the product. The benefits from the investment may exceed the expenses associated with it. It is possible, especially in big enterprises, in which the scale effect occurs. Achieving positive results is more probable if planning is given a high priority, which prevents risk. Other important elements of a planning process, not yet accentuated in this article, are the promotion of the new product in the market, and an attention to compliance with ethical norms, which are accepted by stakeholders. 


\section{Decisiveness of managers}

A decisive manager has the ability to make daring decisions, feels comfortable under pressure, as well as works professionally and relatively quickly. Decisiveness means fluency in making right decisions in various situations. In this article, the reflections have been limited to making strategic choices under risk and uncertainty, hence, in cognitively difficult situations. Under the conditions described, the decision maker is forced to work in a new, complex, and dynamic environment, thus the already acquired knowledge might be of relatively little use.

The determinants of manager's decisiveness may comprise the following cognitive control processes (executive functions) (Di Fabio \& Palazzeschi, 2012; Osman, 2010; Ochsner et al., 2009; Rostowski \& Rostowska, 2012; Vartaniaan, 2011):

1. Big capacity of working memory - corrective thinking, selective attention, complex learning, decision making, logical problem solving, and working under conditions of emotional cognition.

2. Developed metacognition ability — realized through the control of attention (selective, flexible, and reducing the influence of distracters), must be able to make a decision on optimal acting strategy, to define a problem, to keep an interest, to be intentionally involved in solving it, and to act effectively.

3. Efficient cognitive inhibition - makes it possible to eliminate stimuli and inner (psychic) and external (environmental) reactions, considered inappropriate by a manager while solving a decisive problem.

4. Emotional stability - determines efficient planning, organization, maintaining self-control, deferring a reaction, managing with stress, and taking care of safety and relative stability in acting.

5. Big cognitive fluency-enables to discern complex reactions between symbols and to manipulate with those symbols, without regard for a subject's experience and symbols meaning. It determines quick perception and information processing as well as making right decisions in dynamic changes in real time.

6. Self-regulation-facilitates the cooperation in an organization through regulating and controlling emotions, instincts, needs, impulses, and motivation.

The determinants of manager's decisiveness within the framework of affective automatic processes are as follows (Myers, 2013; Wieczorkowska-Wierzbińska, 2011; Csikszentmihalyi, 1990; Russell, 2009; Ma, 2011):

1. Careful approach to handling emotions - treating the affective automatic processes as a very hard to manipulate packet of useful information, applicable in decision-making.

2. The ability to identify emotions content - entire or partial awareness of the subject, the skill to estimate the valence of an emotion (positive and negative) in oneself and others as well as comprehending an influence of every of the affective states on the probable course of decision making and a potential rightness of the final problem solving.

3. The ability to arouse sthenic emotions - in oneself and in others, being a kind of tension increasing the organism energy level, and enabling cognitive and affective activity in a decision making process; the ability to achieve high (and optimal at the same time) cognitive efficiency as a result of arousing the flow-a positive emotion of rather high intensity, which may occur only under conditions of cognitive "adjustment" of a decision-maker to a task (feeling the harmony in the perceptual field). 
4. The awareness of the influence of the emotion intensity and valence on potential cognitive dysfunction in a decision making process

\section{Emotional intelligence}

The quality of cognitive control processes and automatic affective processes determine a manager's work, which requires higher rank cognition, hence making decisions amidst risk and uncertainty.

\section{Conclusion}

Making investment decisions concerning the implementation of the new product (semi-passive autonomous transponder, requiring no battery power, consistent with the EPC standard) in Polish enterprises, requires monitoring and simultaneous estimation of current and future conditions with regard to organizational functions in the following areas:

1. Macro environment - trends and development of new products in technical and technological environment and their influence on an organization.

2. Competitive environment, including:

a. Customer satisfaction-adjusting the product to meet customers' needs and expectations (especially, strategic ones); scaling the possibilities for the wider understood group of customers; identifying types and number of solutions in improving the relations; determining priorities on account of urgency and intensification of customers' needs.

b. Competitive advantage - uniqueness of the product in comparison with competitors' products, branch trends.

c. Providers' possibilities - quality, cost, and, time as essential criteria of the product estimation and its implementation in a organization.

3. Organization strategic potential —effective project management regarding the new product implementation.

4. Managers' decisiveness - considerable decisive skills in the area of cognitive control processes and automatic affective processes.

Taking into consideration the crucial areas in the process of investment decision-making is imperative for the successful product implementation.

\section{Acknowledgements}

This work was supported in part by the Polish National Centre for Research and Development (NCBR) under Grant No. PBS1/A3/3/2012 titled "Synthesis of autonomous semi-passive transponder dedicated to operation in anticollision dynamic RFID systems."

\section{References}

Banaitiene, N., \& Banaitis, A. (2012). Risk Management in Construction Projects, Risk Management - Current Issues and Challenges. In N. Banaitiene (Ed.), Risk Management - Current Issues and Challenges (pp. 429-448). doi:10.5772/51460

Bartneck, N., Klaas, V., \& Schoenherr, H. (2009). Optimizing Processes with RFID and Auto ID. Erlangen: Publicis Publ.

Baysan, S., \& Ustundag, A. (2013). The Cost-Benefit Models for RFID Investments. In A. Ustundag (Ed.), The Value of RFID. Benefits vs. Costs (pp. 13-22). London: Springer-Verlag. doi:10.1007/978-1-4471-4345-1

Brown, D. (2007). RFID Implementation. New York: McGraw-Hill.

Building RFID for the Global Environment (BRIDGE) (n.d.). Retrieved from http://www.bridge-project.eu/ 
Butcher, T., \& Grant, D. B. (2012). Identifying Supply Chain Value Using RFID-enabled Distributed Decision-Making for Food Quality and Safety Assurance. In H. K. Chan, \& F. Lettice (Eds.), Decision-Making for Supply Chain Integration (pp. 89-103). London: Springer-Verlag. doi:10.1007/978-1-4471-4033-7_5

Cevikcan, E., \& Ustundag, A. (2013a). Risk Analysis for RFID Investments Under Uncertainty. In A. Ustundag (Ed.), The Value of RFID. Benefits vs. Costs (pp. 23-34). London: Springer-Verlag. doi:10.1007/978-1-4471-4345-1

Cevikcan, E., \& Ustundag, A. (2013b). Decision Making for Determining the Implementation Level of RFID Projects. In A. Ustundag (Ed.), The Value of RFID. Benefits vs. Costs (pp. 53-67)., London: Springer-Verlag. doi:10.1007/978-1-4471-43451

Chongwatpol, J., \& Sharda, R. (2013). Achieving Lean Objectives through RFID. A Simulation-Based Assessment Decision Sciences, 44(2), 239-266. doi:10.1111/deci.12007

Csikszentmihalyi, M. (1990). Flow: The Psychology of Optimal Experience. New York: Harper and Row.

Coordinating European Efforts for Promoting the European RFID Value Chain (CE RFID) (2014). Retrieved January 30, 2014 from http://www.rfid-in-action.eu/public/

De la Giroday, S. (2010, December). Tracking postal movement, ID World, 40-41.

Di Fabio, A., \& Palazzeschi, L. (2012). Incremental variance of the core self-evaluation construct compared to fluid intelligence and personality traits in aspects of decision-making. Personality and Individual Differences, 53(3), 196-201. http://dx.doi.org/10.1016/j.paid.2012.03.012

General Director for National Roads and Motorways, Ministry of Infrastructure and Development, Electronic Toll Collection System viaTOLL. (2014, January 30). Retrieved from http://www.viatoll.pl/en.

Giusto, D., Iera, A., Morabito, G., \& Atzori, L. (Eds.) (2010). The Internet of Things - 20th Tyrrhenian Workshop on Digital Communications. Berlin: Springer.

Global RFID Interoperability Forum for Standards (GRIFS) (2014). Retrieved January 30, 2014 from http://www.grifsproject.eu/.

Ha, O., Park, M., Lee, K., \& Park D. (2013). RFID Application in the Food-Beverage Industry: Identifying Decision Making Factors and Evaluating SCM Efficiency. KSCE Journal of Civil Engineering 17(7), 1773-1781. doi:10.1007/s12205-0130297-x

Harrison, R. (2009). A practice of vetting RFID. Global Identification, 56-57.

Harrop, P., \& Das, R. (2009). Printed and Chipless RFID Forecasts, Technologies \& Players 2009-2029. IDTechEx.

Hitzer, T. (2010). Security for contactless government ID. Global Identification, 56-59.

Huo, Y., \& Jia, F. (Eds.) (2008). Supply Chain. The Way to Flat Organisation. Vienna, Austria: I-Tech. doi:10.1201/9781420052824

Keating, B. W., Coltman, T. R., Fosso-Wamba, S., \& Baker, V. (2010). Unpacking the RFID investment decision. Proceeding of the IEEE, 98(9), 1672-1680. doi:10.1109/JPROC.2010.2052530

Lee, I., \& Lee, B.-Ch. (2012). Included in Your Digital Subscription Measuring the Value of RFID Investment: Focusing on RFID Budget Allocation. IEEE Transactions on Engineering Management, 59(4), 551-559. doi:10.1109/TEM.2011.2163072

Ma, Ch., Gong, G., \& Ma, Y. (2011). An Information Processing Model for Emotional Agents Based on the OCC Model and the Mood Congruent Effect. In Y. Tang, V-N. Huynh, J. Lawry (Eds.), Integrated Uncertainty in Knowledge Modelling and Decision Making, International Symposium, IUKM 2011, Hangzhou, China, October 28-30, Proceedings (s. 98-108). Verlag Berlin Heidelberg: Springer. doi:10.1007/978-3-642-24918-1

Manish, B., \& Shahram, M. (2005). RFID Field Guide: Deploying Radio Frequency Identification Systems. Prentice Hall PTR.

Myers, D. G. (2013). Psychology (10th ed.). New York: Worth Publishers, 458-511.

Ochsner, K. N., Ray, R. R., Hughes, B., McRae, K., Cooper, J. C., Weber, J., Gabrieli, J. D. E., \& Gross, J. J. (2009). Bottom-up and top-down processes in emotion generation: Common and distinct neural mechanisms. Psychological Science, 20(11), 1322-1331. doi:10.1111/j.1467-9280.2009.02459.x

Osman, M. (2010). Controlling Uncertainty: Decision Making and Learning in Complex Worlds. Chichester, England: Wiley-Blackwell.

Parks, L. (2009). Safeguarding supply chains with RFID. Global Identification, 64-65.

RFID News: The Five-Cent Tag is Here (2009). Supply Chain Digest. Retrieved January 27, 2009 from http://www.scdigest.com 
Rostowski, J. \& Rostowska, T. (2012). Neuropsychological Context of Marital Functioning. In T. Heinbockel (Ed.), Neuroscience (pp. 51-66). Croatia: InTech.

Russell, J. A. (2009). Emotion, Core Affect, and Psychological Construction. Cognition and Emotion, 23(7), 1259-1283, doi:10.1080/02699930902809375

Sarma, S. (2001). Towards the 54 Tag, Auto-ID Center. White Paper WH-006, Cambridge MA: MIT.

Schuster, E. W., Allen, S. J., \& Brock, D. L. (2007). Global RFID - The Value of the EPCglobal Network for Supply Chain Management. Berlin: Springer.

Siricio, L., \& Devenport, M. (2008). Choosing the Best RFID Label Supplier, White Paper, Mid South-RFID and RFID Wizards.com.

Tamm, G., \& Tribowski, C. (2010). RFID. In O. Günther, W. Karl, R. Lienhart, \& K. Zeppenfeld (Eds.), Informatik im fokus. Berlin Heidelberg: Springer-Verlag. doi:10.1007/978-3-642-11460-1

Turcu, C. (2010). Sustainable Radio Frequency Identification Solutions. Intech.

Vartaniaan, O., Mandel D. R. (Eds.) (2011). Neuroscience of Decision Making. New York: Psychology Press.

Wieczorkowska-Wierzbińska, G. (2011). Psychological limitations. Warsow: Scientific Publishing House Faculty of Management of Warsaw University.

Working Group RFID of The ETP EPoSS, Ver. 1.1, (2008, May 27). EU Commision, Information, Society and Media: Internet of Things in 2020 - Roadmap for the Future, INFSO D.4 Networked Enterprise \& RFID, INFSO G.2 Micro \& Nanosystems.

Woźniak, L. (Ed.). (2008). EU Project No. WKP 1/1.4.5/2/2006/21/24/602/2006/U, Priority Technologies for Sustainable Development of Podkarpacie Province, Final Raport, Rzeszow, Poland.

Yan, L., Zhang, Y., Yang, L. T., \& Ning, H. (2008). The Internet of Things - From RFID to the Next-Generation Pervasive Networked Systems, Wireless Networks and Mobile Communications. FL, USA: Auerbach Publications, Taylor \& Francis Group.

Zhou, W., \& Piramuthu, S. (2013). Technology Regulation Policy for Business Ethics: An Example of RFID in Supply Chain Management, Journal of Business Ethics, 116(2), 327-340. doi:10.1007/s10551-012-1474-4 